\title{
Characterization of 'Stoneless': A Naturally Occurring, Partially Stoneless Plum Cultivar
}

\author{
Ann M. Callahan ${ }^{1,2}$, Chris Dardick ${ }^{1}$, and Ralph Scorza \\ U.S. Department of Agriculture-Agricultural Research Service, Appalachian Fruit Research Station, \\ 2217 Wiltshire Road, Kearneysville, WV 25430
}

Additional Index words. Prunus domestica, lignin, fruit endocarp, stone development, pit

\begin{abstract}
The plum (Prunus domestica) cultivar Stoneless was characterized to determine if the lack of stone was the result of reduced endocarp development or a decrease in lignification. Fruit were sampled at several times from 37 days before stone hardening (DBH) until the stone was too hard to cut with a knife and were compared with plum fruit that had normal stones. At all sampling times there was less endocarp tissue and reduced lignin staining in the 'Stoneless' plum fruit. The tissue that did stain appeared to be small endocarp remnants present in the 'Stoneless' plum, and was concentrated at the suture side and at the blossom end as well as the stem end. The lignin stain was detected in these regions beginning at $19 \mathrm{DBH}$, while the normal plums had a progression of staining beginning at the blossom end, suture side at $23 \mathrm{DBH}$ and radiating up to the stem end and throughout the presumptive stone tissue at 8 DBH. Comparison of dry weight for dissected tissues agreed with the specific lack of endocarp tissue in the 'Stoneless' plum. Gene activity for the lignin pathway was analyzed using four known genes required for lignification. All four genes showed endocarp-specific expression in 'Stoneless' similar to that observed for the control. These results support the idea that the phenotype of 'Stoneless' plum fruit is due to a decrease in endocarp formation rather than a decrease in endocarp lignification.
\end{abstract}

The development of seedless cultivars of fruit such as grape (Vitis vinifera), sweet orange (Citrus sinensis), and watermelon (Citrullus lanatus) has significantly increased the consumption of these fruit (Pollack, 2001). The economic potential of doing the same for stone fruit (Prunus) is promising considering the marketing possibilities for pitless cultivars (lacking stone and seed) of cherry ( $P$. cerasus and P. avium), peach (P. persica), plum $(P$. domestica and $P$. salicina), and apricot $(P$. armeniaca), coupled with decreased production costs for canned and dried fruit. Because fruit trees are vegetatively propagated and the seeds are not eaten, pits are generally considered agricultural waste by the processing industry and must be disposed of, typically through burning. Thus, pit removal and disposal substantially raises production costs and contributes to pollution. In addition, the presence of pits and pit fragments in dried and processed fruit is a matter of concern for processors and can lead to product rejection as well as injury to consumers and consequent lawsuits.

Developing pitless stone fruit would require the elimination of the seed and the stone, a hard woody layer surrounding the seed. The goal of developing stoneless plums was first approached by the visionary breeder Luther Burbank in the early 1900s using a wild-type plum that was partially stoneless (Burbank, 1914). He was able to integrate higher fruit quality with the stoneless trait through breeding and even found lines

Received for publication 14 Oct. 2008. Accepted for publication 22 Nov. 2008. We thank Mark Demuth, Linda Dunn, and Elizabeth Lutton for technical assistance and advice, and David Ramming for providing us with the germplasm used in this study.

Mention of a trademark, proprietary product, or vendor does not constitute a guarantee or warranty of the product by the U.S. Department of Agriculture and does not imply its approval to the exclusion of other products or vendors that also may be suitable.

${ }^{1} \mathrm{Co}$-senior authors.

${ }^{2}$ Corresponding author. E-mail: ann.callahan@ars.usda.gov. without seeds, but was never able to completely eliminate the stone or the seed. While Burbank may have failed in his attempt to revolutionize plum production in this way, he left an important legacy by demonstrating that the stone can be essentially eliminated without loss of fruit quality or yield.

Burbank first identified the partially stoneless trait in a wild plum found in France called 'Sans Noyau'. Burbank described this plant as bushy, thorny, and bearing small fruit with incomplete stones about the seed and no known effects on seeds (Burbank, 1914). He crossed this wild plum to commercial cultivars in California but, given that knowledge of genetics was limited at the time, Burbank did not report segregation ratios, thus it is unknown whether it is a single or multigenic trait.

While the function of the stone has not been systematically studied, there is ample evidence that it serves to protect the seed from stress and disease (Doster and Michailides, 1999). In the early 1960s, Ryugo first recognized that stones are composed of lignin $(1961,1963)$. His work documented the fact that peach stones are rich in lignin, the seasonal pattern of lignin accumulation, and the presence of lignin biosynthesis intermediates. These studies and others have shown an increase in stone dry weight and lignification that begins in the second stage of fruit development until maturity (Nakano and Nakamura, 2002; Ryugo, 1961). Studies in peach directed toward increasing fruit size, especially of fruit in which the embryo was destroyed by cold temperatures, have shown the effect of growth regulators on embryo and stone development (Zucconi and Bukovac, 1978). Crane et al. (1961) showed that stone development was related to fruit growth, which was affected by applied gibberellic acid (GA) concentrations. Crane (1963) concluded that subnormal growth and ultimate size of the stone in parthenocarpic peaches was due to restricted cell enlargement, with cell division a contributing factor. He found that lignification proceeded normally, regardless of the ultimate growth of the stone. 
The majority of studies on lignin and its regulation have been performed on tree crops for pulp and paper production or on forage crops for improved digestibility. The recent interest in biofuels has sparked intense interest in lignin research, as large amounts of mostly inaccessible energy are stored in plants as lignin. This work has identified most of the genes for the major enzymes in the pathway and the potential regulatory points (reviewed by Boerjan et al., 2003). Lignin is formed from the phenylpropanoid pathway, the end products of which are coniferyl and sinapyl alcohols. These lignin monomers serve as the basis for lignification, which is the process of producing the lignin polymer via oxidative processes aided by peroxidases and laccases.

Here, we set out to study the physiological basis for the stoneless trait. The lack of hard stone tissue could be the result of two different mechanisms: 1) hardening via lignification does not effectively take place in 'Stoneless', leaving regions where the endocarp layer is present but does not harden or 2) incomplete endocarp formation that results in fragmented stones.

\section{Materials and Methods}

Plant material. The stoneless plum germplasm used in this study, 'Stoneless', was obtained from D. Ramming (U.S. Department of Agriculture, Agricultural Research Service, Parlier, CA). These trees grow and fruit as typical P. domestica plums with the exception of producing incomplete stones. It is not clear which of Burbank's selections or cultivars these clones represent except that they are probably not the original 'Sans Noyau', as the trees are not bushy nor are the fruit small. 'Stoneless' is the first $P$. domestica to bloom in the Appalachian Fruit Research Station (AFRS) orchard and most years produces very small numbers of fruit under our growing conditions. Samples used in this study were taken in 2006 and 2008, as very few fruit were obtained in 2007 . The $P$. domestica cultivar Cacanska lepotica, which flowered with 'Stoneless' in 2008, was used as a control. The 2008 collection was used for all studies with the exception of the whole fruit gene expression studies for 'Stoneless' and consisted of five to 10 similar-staged fruit, each harvested at $37,23,19,15,8$, and $0 \mathrm{~d}$ before stone hardening $(\mathrm{DBH})$ [equivalent to $24,38,42,46,53$, and 61 $\mathrm{d}$ after $50 \%$ bloom (DAB)] from randomly chosen branches of a single 10-year-old tree of 'Cacanska lepotica', which is wild type for stone formation and from branches of two 8-year-old trees of 'Stoneless', all grown on seedling $P$. domestica rootstocks. Subsets of these fruit series were used for the lignin staining studies and gene expression studies in dissected fruit. Whole fruit gene expression studies for 'Stoneless' were derived from three to five fruit per time point collected in 2006 at 25, 22, 14, 8, 5, and $0 \mathrm{DBH}$ from three 6-year-old trees of 'Stoneless'. Additional fruit were collected at the same time for lignin staining. In all years, fruit were unthinned and trees received $\approx 40 \mathrm{~kg} \cdot \mathrm{ha}^{-1} \mathrm{~N}$ per year. Pesticide and fungicide applications were applied as necessary using recommended materials and rates (Pfeiffer et al., 2008)

Determination of STONe CONTENT. Five to 10 whole fruit were collected each from one 'Cacanska lepotica' and two 'Stoneless' trees at 23, 19, 15, 8, and $0 \mathrm{DBH}$ and were separated into exocarp, mesocarp, endocarp, and seed using a scalpel blade. To obtain more accurate dry weights, each tissue sample was pooled, flash frozen in liquid nitrogen, and lyophilized for
$6 \mathrm{~d}$. Samples from multiple fruit were pooled due to limitations on the number of samples that could be simultaneously lyophilized. Weights of the pooled samples were measured and the average fraction of total fruit weight for each component was calculated. The weights from the two 'Stoneless' trees were averaged.

Lignin STAINING. Developing 'Stoneless' and 'Cacanska lepotica' fruit were collected from 37 to $0 \mathrm{DBH}$, at which point the stone could only be cut with clippers. Fruit sections were stained for lignin formation using phloroglucinol- $\mathrm{HCl}$, which reveals the presence of lignin before stone hardening (Dean, 1997). Cut fruit were placed in a phloroglucinol solution [1\% $(\mathrm{w} / \mathrm{v})$ phloroglucinol, $12 \% \mathrm{HCl}(\mathrm{v} / \mathrm{v})$, and $85 \%$ ethanol $(\mathrm{v} / \mathrm{v})]$ for $1 \mathrm{~h}$. The fruit were then rinsed in $95 \%$ ethanol $(\mathrm{v} / \mathrm{v})$ and photographed.

Quantitative PCR. Fruit for RNA extractions was frozen in liquid nitrogen and lyophilized for at least six days. RNA extractions were performed as previously described (Callahan et al., 1992) with $\approx 0.5 \mathrm{~g}$ of dry material for every $10 \mathrm{~mL}$ of extraction buffer. RNA was treated with DNase using a DNAfree or Turbo DNA kit (Ambion, Woodland, TX) according to the protocol provided by the manufacturer. The RNA was then precipitated with $0.3 \mathrm{M}$ sodium-acetate and 2.5 volumes of $95 \%$ ethanol (v/v), quantified on a Nanodrop spectrophotometer (NanoDrop, Wilmington, DE), and qualified on a Bioanalyzer (Agilent, Santa Clara, CA). Quantitative polymerase chain reactions (qPCR) were run in triplicate for each RNA using $50 \mathrm{ng}$ of RNA in a $15-\mu \mathrm{L}$ reaction using Superscript III Platinum SYBR Green qRT-PCR Kit (Invitrogen, Carlsbad, $\mathrm{CA})$ with the reverse transcriptase reaction and subsequent amplification in the same tube (1-step qPCR). The four genes monitored were phenylalanine ammonia-lyase (PAL) and cinnamate 4-hydroxylase $(\mathrm{C} 4 \mathrm{H})$, which initiate lignin biosynthesis, caffeoyl coenzyme A 0-methyltransferase, (CCoAOMT) which catalyzes intermediate steps, and a peroxidase (PR), which facilitates the final step of tissue hardening via lignin polymerization (reviewed by Boerjan et al., 2003) (Table 1). C4H and PR primer sequences were designed from Malus ESTs, while PAL and CCoAOMT primers were designed from Prunus sequences. The primer sequences and sources are listed in Table 1. Reactions were performed in triplicate on a 7900 DNA Sequence detector (Applied Biosystems, Foster City, CA) and were quantified using a relative curve based on a standard RNA diluted and run at the same time with each primer pair. A primer pair designed to amplify $26 \mathrm{~S}$ ribosomal RNA was run separately with all samples and was used to normalize the data. A dissociation curve was run to verify the amplified product from the melting profile obtained for each reaction. Average expression for each RNA was determined from the highly consistent triplicate reactions, with the range of the reactions never more than 0.5 threshold cycle $(\mathrm{Ct}) . \mathrm{Ct}$ is a measure of the time at which the PCR product reaches a fixed threshold.

\section{Results}

IMMATURE 'STONELESS' FRUIT LACK A COMPLETE ENDOCARP. 'Stoneless' fruit observed over several growing seasons revealed fruit-to-fruit variation in stone phenotypes. More complete stones were obtained in 2005 and 2007, while little stone tissue was observed in 2008. Ripe fruit ranged from having only small fragments of stone to larger and in some cases nearly 
Table 1. Genes and primer pairs used to analyze the lignin pathway gene expression in 'Stoneless' and wild-type plums by quantitative real-time PCR.

\begin{tabular}{|c|c|c|c|}
\hline Gene $^{z}$ & Accession no. ${ }^{y}$ & Primer sequence ${ }^{\mathrm{x}}$ & $\begin{array}{c}\text { Product size } \\
\text { (nucleotides) }^{\mathrm{w}}\end{array}$ \\
\hline \multirow[t]{2}{*}{$\overline{\mathrm{PAL}}$} & AF206634.1 & For-ACCATGTCCAAAGTGCAGAGCA & 97 \\
\hline & & Rev-AGCTTCAATACGTCCACAGCCT & \\
\hline \multirow[t]{2}{*}{$\mathrm{C} 4 \mathrm{H}$} & EB139247.1 & For-TTGAAGTGCGCCATTGACCACA & 98 \\
\hline & & Rev-GCAGCAACATTGATGTTCTCGACG & \\
\hline \multirow[t]{2}{*}{ CCOAOMT } & BU044203.1 & For-GCTCATCAATGCCAAGAACACC & 136 \\
\hline & & Rev-ACGACCCAAGTCATAGTTTTCCC & \\
\hline \multirow[t]{2}{*}{ PR } & EB140044.1 & For-TGAGTGGCTCCAACAGCAACAT & 124 \\
\hline & & Rev-TTCCAATGGTGTGGCTTCCAGA & \\
\hline \multirow[t]{2}{*}{$26 \mathrm{~S}$} & BF717196.1 & For-GCAGCCAAGCCTTCATAGCG & 216 \\
\hline & & Rev-GTGCGAATCAACGGTTCCTC & \\
\hline
\end{tabular}

${ }^{\mathrm{z}} \mathrm{PAL}=$ phenylalanine ammonia-lyase, $\mathrm{C} 4 \mathrm{H}=$ cinnamate 4 -hydroxylase, $\mathrm{CCoAOMT}=$ caffeoyl CoA, $\mathrm{O}$-methyltransferase, $\mathrm{PR}=$ peroxidase, $26 \mathrm{~S}=26 \mathrm{~S}$ ribosomal RNA.

${ }^{\mathrm{y}}$ GenBank accession number for the corresponding gene sequence.

${ }^{\mathrm{x}}$ Nucleic acid sequence of the forward (For) and reverse (Rev) primers derived from the sequence represented by the corresponding accession number.

${ }^{\text {w }}$ Size of the product produced from the corresponding primer pair in nucleotide bps.

complete stones (Fig. 1). The majority of stone tissue was located along the margins, parallel with the suture, with additional small remnants found scattered throughout. 'Stoneless' fruit typically contained an open cavity where the stone tissue would normally be found (Fig. 1).

To monitor endocarp development over time, 'Cacanska lepotica' and 'Stoneless' fruit series were examined. At early stages of fruit development, the presumed endocarp layer is visibly white in color and the presumed mesocarp is green [it is presumed based on the subsequent lignin staining and hardening of the white endocarp layer as well as from thin section studies of Prunus pensylvanica and Prunus virginiana (Labrecque et al., 1985a, 1985b)] (Fig. 2). Decreased endocarp formation in 'Stoneless' plum was observed as early as 37 DBH. Differences were primarily found around the central region of the stone where 'Stoneless' had little visible endocarp, while larger regions of endocarp could be found at the stem and blossom ends, extending around the suture margins.

Patterns of Lignin Deposition. Endocarp began to stain for lignin in 'Stoneless' and 'Cacanska lepotica' by 23 DBH (Fig. 3). By $19 \mathrm{DBH}$, stained fragments of endocarp were primarily found at the blossom ends in a small sliver extending around the margins of the suture. Staining spread in the 'Cacanska lepotica' to the entire endocarp layer and hardening continued until the stone tissue could no longer be cut with a scalpel (0 DBH). In 'Stoneless', on the other hand, lignin staining was primarily limited to the area adjacent to the suture though small random areas of lignin deposition could also be observed (Fig. 3 ). There was a fine net of white tissue next to the seed that did not stain or harden.

TOTAL WEIGHT OF ENDOCARP TISSUE IS REDUCED IN 'STONELESS'. Overall stone content relative to whole fruit was determined from 23 through $0 \mathrm{DBH}$. Developing fruit were sectioned by scalpel blade into exocarp, mesocarp, endocarp, and seed. Again, the white tissue was presumed to be the endocarp layer based on subsequent staining for lignin and hardening of that layer. The dry weights were recorded and compared (Fig. 4). Results showed that the dry endocarp weights as a percentage of total dry fruit weight were measurably different between 'Stoneless' $(\approx 20 \%$ stone and $\approx 80 \%$ flesh) and 'Cacanska lepotica' ( $\approx 40 \%$ stone and $\approx 60 \%$ flesh) beginning at $19 \mathrm{DBH}$. 'Stoneless' endocarp dry weight was about half of the amount of 'Cacanska lepotica' endocarp by 15 DBH.

INDUCTION OF PHENYLPROPANOID PATHWAY GENES IN STONE FRAGMENTS. To verify that lignin biosynthetic pathways function normally during stone hardening in 'Stoneless' fruit, qPCR was used to monitor the expression of four lignin pathway genes that had previously been found to be specifically induced in the endocarp just before lignin deposition and stone hardening in peach (C. Dardick and A.M. Callahan, unpublished data). The expression pattern of $\mathrm{C} 4 \mathrm{H}, \mathrm{PAL}$, and $\mathrm{PR}$ in whole fruit (minus seed) displayed a similar pattern of high expression during the onset of lignin deposition followed by a drop in expression as the endocarp hardened (Fig. 5). To verify that the observed lignin pathway gene expression was associated with the endocarp tissue, PAL, C4H, CCoAOMT, and PR expression was monitored in specific tissue to assess the spatial pattern of gene expression within the fruit (Fig. 6). In all four cases, gene expression was higher in the endocarp tissue than the mesocarp and exocarp tissue together. The expression level in endocarp relative to the expression level in mesocarp + exocarp was roughly equivalent in 'Cacanska lepotica' and 'Stoneless'.

\section{Discussion}

The observations presented in the current study support the hypothesis that 'Stoneless' plums do not fully form the endocarp layer. In developing fruit, there appears to be less endocarp tissue, which can be seen as early as $37 \mathrm{DBH}$. This continues to be the case as lignin deposition initiates and as the stone hardens. Lignification and stone hardening take place at about the same time in 'Stoneless' and 'Cacanska lepotica'. Tissue dissections suggest that there is about half the endocarp/ stone tissue in 'Stoneless' as there is in 'Cacanska lepotica'. The majority of endocarp tissue present in 'Stoneless' is found around the margins of the seed cavity, near the blossom end. After hardening, this fragment produces a small crescentshaped sliver that typically makes up the majority of the stone 



Fig. 1. Fruit of 'Stoneless' plum depicting phenotypic features. (A-B) The range of phenotypes observed in 2005 from very little stone tissue to more extensive stone development, respectively. Transverse sections of 'Stoneless' (C) and 'Cacanska lepotica' (D) plums collected in 2008 highlight the cavity surrounding the seed observed in 'Stoneless' fruit. These same fruit cut longitudinally (E) reveal the concentration of stone tissue in 'Stoneless' (left) around the margins and parallel to the suture.

A

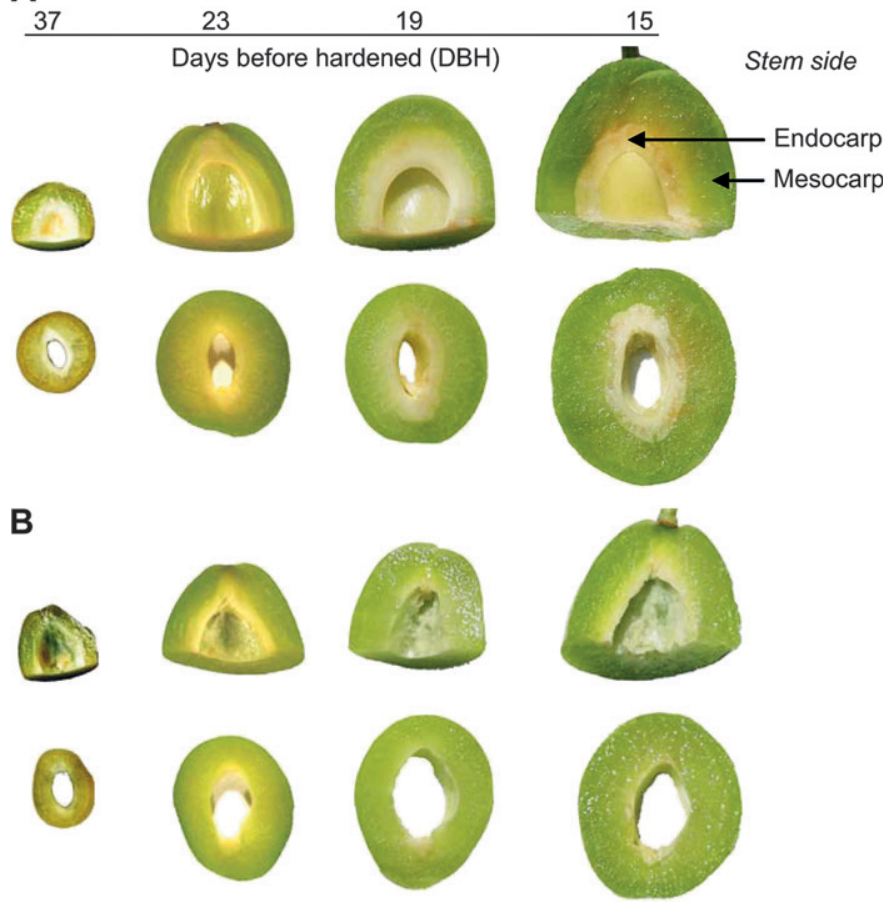

Fig. 2. Sections from developing fruit of 'Cacanska lepotica' (A) and 'Stoneless' (B) plums before stone hardening. All fruit are oriented with the stem side up. Fruit quarters and circular slices are shown. Endocarp tissue appears white in color. Fruit stage is shown as days before hardened, indicated at top.

tissue. This region is centered over the seed attachment site and is consistent with the location of the funiculus, a structure that attaches the ovule to the placenta (Esau, 1953; Gradziel and Dandekar, 2001; Iglesias-Fernandez et al., 2007). It is also the location where lignin deposition initiates in 'Stoneless' and 'Cacanska lepotica'. In addition to the prominence of the
A

\begin{tabular}{lll}
19 & 15 & 0 \\
\hline & Days before hardened (DBH)
\end{tabular}
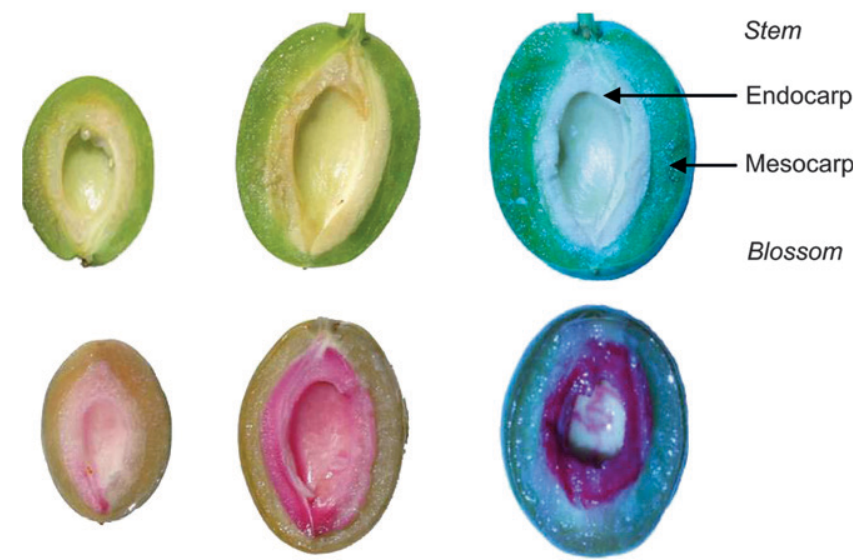

B


Fig. 3. Half sections from developing fruit of 'Cacanska lepotica' (A) and 'Stoneless' (B) plums taken during the stone hardening process. Unstained (top row) fruit and fruit stained for lignin with phloroglucinol- $\mathrm{HCl}$ (bottom row) are shown. All fruit are oriented with the stem side up. 


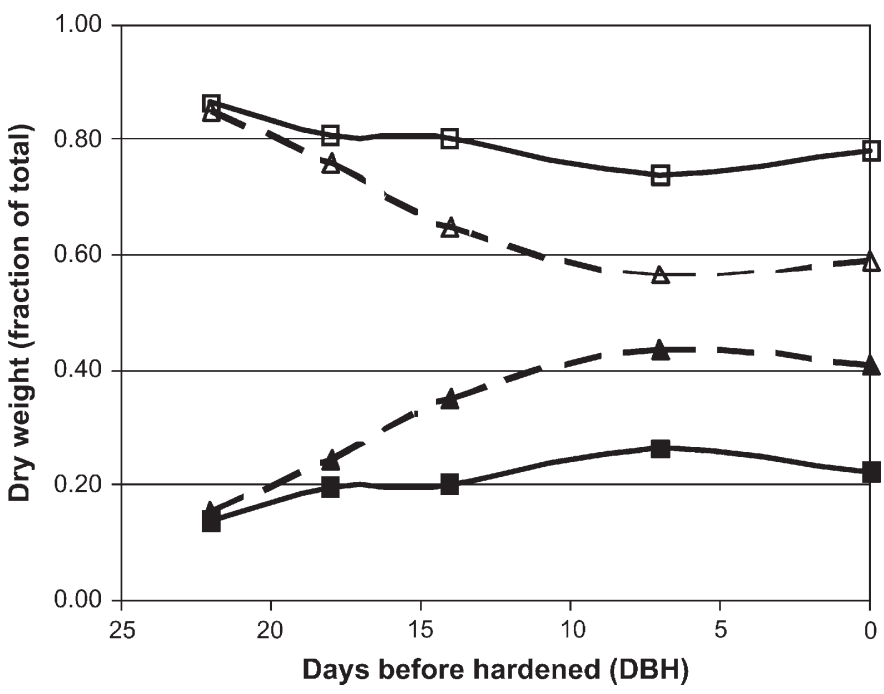

Fig. 4. Comparison of the weights of stone tissue and flesh with skin tissue of 'Stoneless' and 'Cacanska lepotica' plums. Graph shows the fraction of dry weight of the tissue relative to the total dry weight of the fruit minus the seed. 'Stoneless' is represented by a solid line with squares and 'Cacanska lepotica' is represented by a dashed line with triangles. The open symbols represent flesh + skin and the closed symbols represent stone tissue. The weights of the 'Cacanska lepotica' tissue is based on a pool of five to 10 fruit and the weights of the 'Stoneless' are based on the average of two pools of five to 10 fruit. The dry weight of 'Cacanska lepotica' stone tissue increases to a greater extent after $22 \mathrm{~d}$ before hardened than does that of the 'Stoneless' fruit.



Fig. 5. Expression of lignin pathway genes in whole fruit (excluding seed) of 'Stoneless' plum measured by qPCR. Expression of phenylalanine ammonialyase [PAL (diamonds)], cinnamate 4-hydroxylase [C4H (squares)], and a peroxidase (triangles) is indicated as relative expression values. Values were converted to fractions of the highest value for visualization on the same scale. $\mathrm{SE}$ is shown by error bars. Maximum PAL, C4H, and peroxidase gene expression occurs just before the onset of lignin deposition $(\approx 19 \mathrm{~d}$ before hardened) and rapidly drops off as lignin polymerizes and stones harden.

funicular region in 'Stoneless' plum endocarp, other small fragments of endocarp tissue can be found scattered throughout the inner portion of the fruit. All of the observable endocarp tissue lignifies, resulting in the fragmented stone phenotype observed in these fruit with the exception of the whitish net-like tissue close to the seed. In some years, we have noticed larger more complete stones in a small number of 'Stoneless' fruit, suggesting that the phenotype may also be environmentally

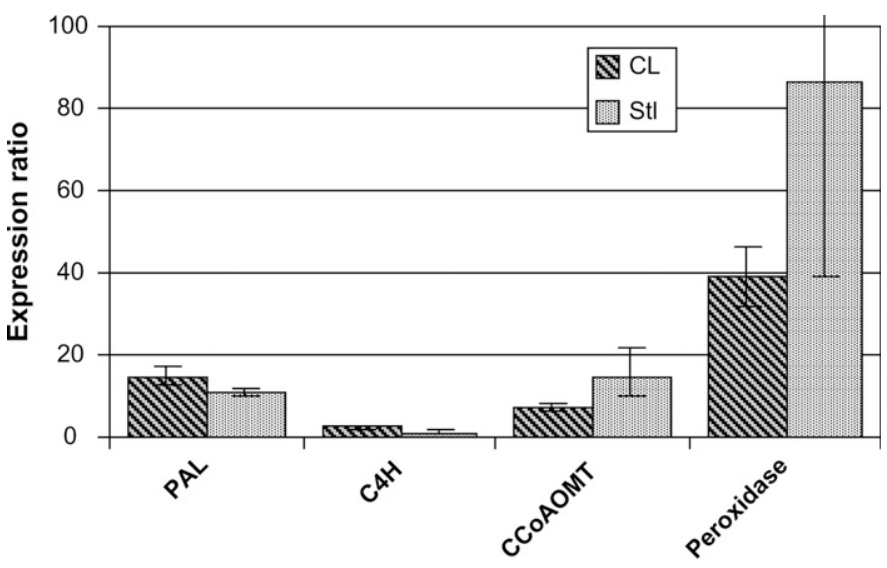

Fig. 6. Stone-specific expression of lignin pathway genes in 'Cacanska lepotica' (CL) and 'Stoneless' (Stl) plums at $19 \mathrm{~d}$ before hardened. RNA was derived from dissected endocarp tissue or mesocarp + exocarp. Lignin pathway genes are indicated along the $\mathrm{x}$-axis. The ratio of expression between the endocarp and the mesocarp + exocarp is shown along the y-axis. For example, phenylalanine ammonia-lyase (PAL) gene expression in Stl is 10 fold higher in the endocarp than the mesocarp + exocarp samples. Error bars indicate SE. Expression of all four genes is substantially higher in endocarp tissue than mesocarp + exocarp samples of 'Cacanska lepotica' and 'Stoneless' plums. The relative ratios of gene expression (endocarp/mesocarp + exocarp) are also similar in both plum cultivars; $\mathrm{C} 4 \mathrm{H}=$ cinnamate 4-hydroxylase, CCoAOMT $=$ caffeoyl CoA.

regulated (data not shown). Taken together, these data suggest that the 'Stoneless' trait is associated with reduced endocarp content. This loss of endocarp may not impact the funicular region, normally embedded within the endocarp, which could comprise the majority of the observed stone tissue.

Although the endocarp tissue is reduced in 'Stoneless' plums, the expression of lignin pathway genes is relatively normal. Expression of PAL, C4H, and a PR show substantial induction in 'Stoneless' during the initiation of lignin deposition. In dissected fruit, PAL, C4H, CCoAOMT, and a PR showed endocarp-specific expression in 'Stoneless' and 'Cacanska lepotica' near the onset of lignin deposition (19 DBH). Collectively, these data point to a mechanism in which the 'Stoneless' phenotype results from a developmental abnormality in endocarp development while lignification pathways remain functional in the small endocarp fragments that remain in addition to the funiculus. It is currently unknown if the mutation responsible for the stoneless phenotype is a single or multigenic trait.

Like many crops, fruit tree science has begun a dramatic revolution due in part to the availability of new technologies such as low-cost genome sequencing, more efficient marker techniques, and functional genomics. To efficiently leverage these technologies and discover the functions of individual genes, documented phenotypic variation within crop germplasm will be critical. The characterization of the 'Stoneless' mutant provides an opportunity to determine the developmental basis for endocarp formation and identify key regulatory factors that control its inception. Understanding the molecular and genetic basis for this stoneless trait could lead to new and innovative ways to engineer stoneless fruit cultivars in the future.

\section{Literature Cited}

Boerjan, W., J. Ralph, and M. Baucher. 2003. Lignin biosynthesis. Annu. Rev. Plant Biol. 54:519-546. 
Burbank, L. 1914. The stoneless plum: An experiment in teaching a plant economics. 21 Nov. 2008. <http://digicoll.library.wisc.edu/cgi-bin/ HistSciTech/HistSciTech-idx?type=article\&did=HISTSCITECH.0011. 0029.0009\&isize $=\mathrm{M}>$.

Callahan, A.M., P.H. Morgens, P. Wright, and K.E. Nichols, Jr. 1992. Comparison of pch313 (pTOM13 homolog) RNA accumulation during fruit softening and wounding of two phenotypically different peach cultivars. Plant Physiol. 100:482-488.

Crane, J.C. 1963. Parthenocarpic peach development as influenced by time of gibberellin application. Proc. Amer. Soc. Hort. Sci. 83:240247.

Crane, J.C., C.A. Rebeiz, and R.C. Campbell. 1961. Gibberellininduced parthenocarpy in the 'JH Hale' peach and the probable cause of 'Button' production. Proc. Amer. Soc. Hort. Sci. 78:111-118.

Dean, J.F.D. 1997. Lignin analysis, p. 199-215. In: W.V. Dashek (ed.). Methods in plant biochemistry and molecular biology. CRC Press, Boca Raton, FL.

Doster, M.A. and T.J. Michailides. 1999. Relationship between shell discoloration of pistachio nuts and incidence of fungal decay and insect infestation. Plant Dis. 83:259-264.

Esau, K. 1953. Plant anatomy. Wiley, New York.

Gradziel, T.M. and A.M. Dandekar. 2001. Field performance of seed and endocarp based resistance to preharvest aflatoxin contamination in almond. Proc. 14th Aflatoxin Elimination Workshop. p. 82.

Iglesias-Fernandez, R., A.J. Matilla, M.C. Roriguez-Gacio, C. Fernandez-Otero, and F. de la Torre. 2007. The polygalacturonase gene
PdPG1 is developmentally regulated in reproductive organs of Prunus domestica L. subsp. insititia. Plant Sci. 172:763-772.

Labrecque, M., D. Barabe, and J. Vieth. 1985a. Developpement de la drupe de Prunus pensylvanica L.f. (Rosaceae). Annales des Sciences Naturelles Botanique 7:39-53.

Labrecque, M., D. Barabe, and J. Vieth. 1985b. Developpement du fruit de Prunus virginiana (Rosaceae). Can. J. Bot. 63:242-251.

Nakano, M. and M. Nakamura. 2002. Cracking and mechanical properties of the stone in peach cultivars after severe thinning. Acta Hort. 592:531-536.

Pfeiffer, D.G., J.C. Bergh, R.D. Fells, R. Yuan, K.S. Yoder, J.F. Derr, M.J. Weaver, and J. Parkhurst. 2008. 2008 Virginia, West Virginia, and Maryland commercial spray bulletin. 12 Nov. 2008. <http:// www.ext.vt.edu/pubs/treefruit/456-419/456-419.html $>$.

Pollack, S. 2001. Consumer demand for fruits and vegetables: The U.S. example, p. 49-54. In: Regmi, A. (ed.). Changing structure of global food consumption and trade. Economic Res. Serv., U.S. Dept. Agr. Publ. WR-S-01-1.

Ryugo, K. 1961. The rate of dry weight accumulation by the peach pit during the hardening process. Proc Amer. Soc. Hort. Sci. 78:132137.

Ryugo, K. 1963. Changes in methoxyl content in the peach endocarp and some of its soluble phenolic constituents during lignification. Amer. Soc. Hort. Sci. 84:110-115.

Zucconi, F. and M.J. Bukovac. 1978. Stimulation of growth of frost-injured peach fruit by gibberellin $\mathrm{A}_{3}$. Acta Hort. 80:159-162. 